\title{
Geomorphological factors influencing hysteresis patterns between suspended load and flow rate in Alpine rivers
}

\author{
Clément Misset ${ }^{1, *}$, Alain Recking ${ }^{1}$, Cédric Legout ${ }^{2},{\text { Alain } \text { Poirel }^{3} \text { and Marine Cazilhac }}^{3}$ \\ ${ }^{1}$ Université Grenoble Alpes, Irstea, UR ETGR, St-Martin-d'Hères, France \\ ${ }^{2}$ Université Grenoble Alpes, IGE - UMR 5564, Grenoble, France \\ ${ }^{3}$ EDF - Division Technique Générale (DTG), Grenoble, France
}

\begin{abstract}
Suspended sediment load represents a large part of total solid fluxes transported in most rivers. Thus, for hydropower plan management or for environmental issues, it is crucial to understand how these sediments are produced, stored and transported in a given catchment. Hysteresis loops in discharge-suspended load signals are commonly used to assess sediment sources and production processes but most of the time the shape of this relation is analyzed qualitatively on short time series or for few events. In this study we analyzed quantitatively 10 long time series of suspended sediment load of various alpine catchments. This method allows us to compare events and to assess to which extent fine sediments originate from hillslope erosion processes or from river bed remobilization. We found that watersheds with braided bed morphology are dominated by clockwise loops while those with narrower bed as step-pool morphology are dominated by counter-clockwise hysteresis or have no general trend. These results suggest that storage and remobilization of fine sediments within the bed could play a major role in suspended sediment transport in Alpine streams, especially in large braided rivers.
\end{abstract}

\section{Introduction}

Suspended sediment load (SSL) is associated to important environmental issues such as nutriment and pollutant transport or alteration of spawning habitat. It also generates reservoir siltation which leads to security issues and loss of profitability. However, SSL is highly variable and still poorly understood, especially in mountainous areas. A part of this variability is often explained because of different zones from which fine sediments originate. Suspended sediments are transported more or less at the mean flow velocity which is lower than the flow wave celerity. Thus, if the main source of sediment is far enough (hillslope or first order tributary) from the observation point, a delay between suspended sediment concentration (SSC) wave and the flow rate (Q) wave will be observed $[1,2]$. This will create a counter-clockwise loop in the SSC-Q relation (Figure 1-a). On the opposite, if the main sediment source is close to the observation point and if it is supply

\footnotetext{
* Corresponding author: clement.misset@irstea.fr
} 
limited (river bed), the SSC will first increase with Q during the rising limb and decrease faster than Q during falling limb because of a rapid flushing of fine sediments stocks [3]. It generates a clockwise loop in the SSC-Q relation (Figure 1-b). If sediment supply is unlimited and if there is no delay due to transport from distant areas, no hysteresis will be observed $[2,4,5]$ as shown on Figure 1-c.
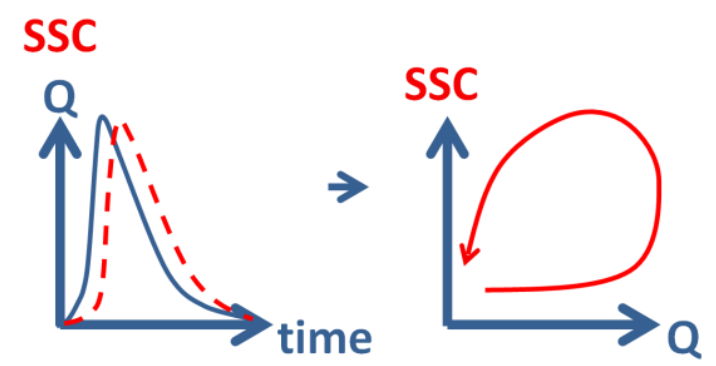

a - Counterclockwise hysteresis: distant sediment sources
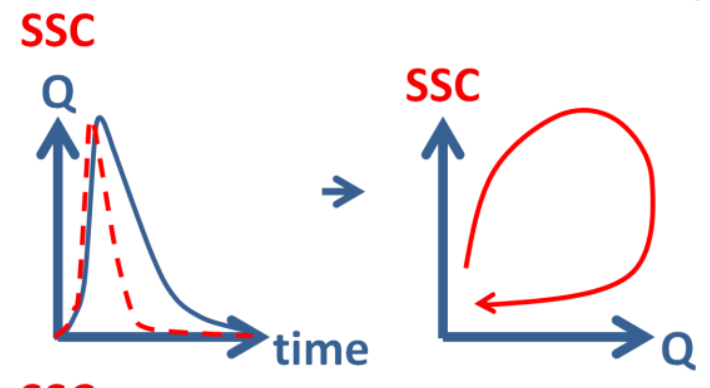

\section{SSC}
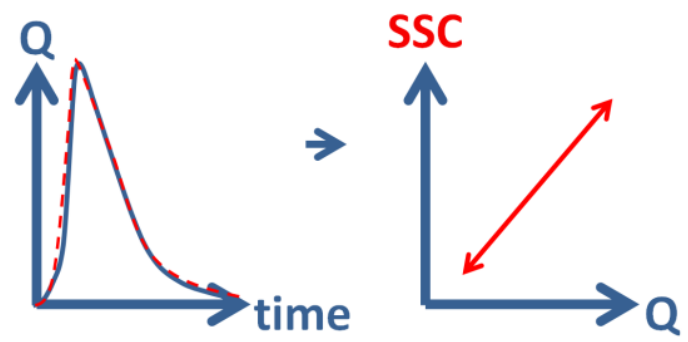

b - Clockwise hysteresis: close sediment sources

c - No hysteresis: unlimited sediment supply

Fig. 1. Conceptual definition of different hysteresis loops between SSC and Q.

These hysteresis loops were described and analysed in many papers to try to understand sediment production processes at the catchment scale. Most of the time, it was done qualitatively on short time series or on few basins. In this study we used 10 times series of SSL measured in the French Alps. A quantitative hysteresis index (HI) developed by Lloyd was used [6]. It allowed us to assess the dominant production processes depending on the catchment and riverbed characteristics.

\section{Material and methods}

\subsection{Studied catchments}

SSL measurements made on ten contrasted Alpine catchments were used to analyse dominant hysteresis trends in the French Alps (Table 1). Five of them are located in the southern pre-Alps (Asse, Bléone, Bès and Buëch rivers). Their hydrology is characterised by a high flow period in winter and at the end of autumn and a low flow period in summer. 
Five other catchments (Arc, Glandon, Arvan, Ferrand and Romanche rivers) are located in high mountain areas with presence of glaciers. They are characterised by a high flow period during the melting season at the end of spring and beginning of summer. The Drac river has an intermediate hydrological regime with a snow melt period in spring, low-flows in summer and high flows in autumn due to heavy rainfall. The size of these basins ranges from 80 to almost $900 \mathrm{~km}^{2}$ comprising various bed morphologies (step pool, plane bed, riffle pool and braided) and a wide range of active widths and slopes. The geology is also variable from one catchment to another. However, large areas can be easily eroded with a maximum of $51 \%$ of no or low vegetation cover and the absence of resistant rocks for some of the watersheds.

Table 1. Catchment characteristics. Catchment size (A), no/low vegetation cover (No), forest cover (Fo), glaciers cover ( $\mathrm{Gl}$ ), soft coherent rocks (SFR), heterogeneous rocks (HR), resistant rocks (RR), mean specific discharge (q), median active width (W), mean slope of the river bed (S).

\begin{tabular}{lcccccccccc}
\hline $\begin{array}{l}\text { Basins } \\
\text { names }\end{array}$ & $\begin{array}{c}\mathrm{A} \\
{\left[\mathrm{km}^{2}\right]}\end{array}$ & $\begin{array}{c}\text { No } \\
{[\%]}\end{array}$ & $\begin{array}{c}\text { Fo } \\
{[\%]}\end{array}$ & $\begin{array}{c}\text { Gl } \\
{[\%]}\end{array}$ & $\begin{array}{c}\text { SFR } \\
{[\%]}\end{array}$ & $\begin{array}{c}\text { HR } \\
{[\%]}\end{array}$ & $\begin{array}{c}\text { RR } \\
{[\%]}\end{array}$ & $\begin{array}{c}\mathrm{q} \\
{\left[1 / \mathrm{s} / \mathrm{km}^{2}\right]}\end{array}$ & $\begin{array}{c}\text { W } \\
{[\mathrm{m}]}\end{array}$ & $\begin{array}{c}\mathrm{S} \\
{[\%]}\end{array}$ \\
\hline Asse & 375 & 10 & 41 & 0 & 9 & 70 & 21 & 12 & 40.3 & 0.87 \\
Bléone & 896 & 14 & 41 & 0 & 19 & 68 & 11 & 8 & 202 & 0.82 \\
Bès & 165 & 14 & 43 & 0 & 42 & 46 & 11 & 17 & 18.7 & 2.57 \\
Buech & 723 & 12 & 47 & 0 & 83 & 1 & 12 & 19 & 87.3 & 0.81 \\
Drac & 510 & 35 & 20 & 0 & 32 & 34 & 18 & 27 & 79.3 & 1.01 \\
Arc & 635 & 49 & 11 & 9 & 0 & 64 & 36 & 30 & 26.4 & 1.12 \\
Glandon & 110 & 31 & 28 & 2 & 0 & 57 & 43 & 23 & 8.4 & 5.8 \\
Arvan & 220 & 24 & 18 & 2 & 38 & 61 & 1 & 32 & 13.6 & 5.92 \\
Ferrand & 80 & 47 & 4 & 5 & 11 & 75 & 14 & 16 & 7.1 & 8.33 \\
Romanche & 230 & 51 & 4 & 12 & 25 & 33 & 42 & 33 & 13.1 & 4.17 \\
\hline
\end{tabular}

The monitoring of SSL on these catchments was made by EDF Company, IRSTEA and IGE research institutes. Measurements made on the Bès and Bléone rivers were already presented in [7]. Available time series ranged from two to ten years (Table 2). SSC was measured through turbidity after a calibration with direct sampling measurements. SSL was obtained by multiplying Q with SSC assuming a uniform SSC over the cross section. The lower measurement frequency on these stations was one hour. Thus, this frequency was used for all-time series to be able to compare them.

Table 2. Available time series of SSL (grayed cells) for the 10 Alpine Rivers.

\begin{tabular}{lllllllllll}
\hline River & 2007 & 2008 & 2009 & 2010 & 2011 & 2012 & 2013 & 2014 & 2015 & 2016 \\
\hline Asse & & & & & & & & & & \\
Bléone & & & & & & & & & & \\
Bès & & & & & & & & & & \\
Buech & & & & & & & & & & \\
Drac & & & & & & & & & & \\
Arc & & & & & & & & & & \\
Glandon & & & & & & & & & & \\
Arvan & & & & & & & & & & \\
Ferrand & & & & & & & & & & \\
Romanche & & & & & & & &
\end{tabular}




\subsection{Hysteresis analysis tools}

To analyze quantitatively hysteresis loops between SSC and Q, the index developed by Lloyd et al. (2016) was used [6]. This index is unbiased. It allows to compare the strength and the direction of the hysteresis patterns between events.
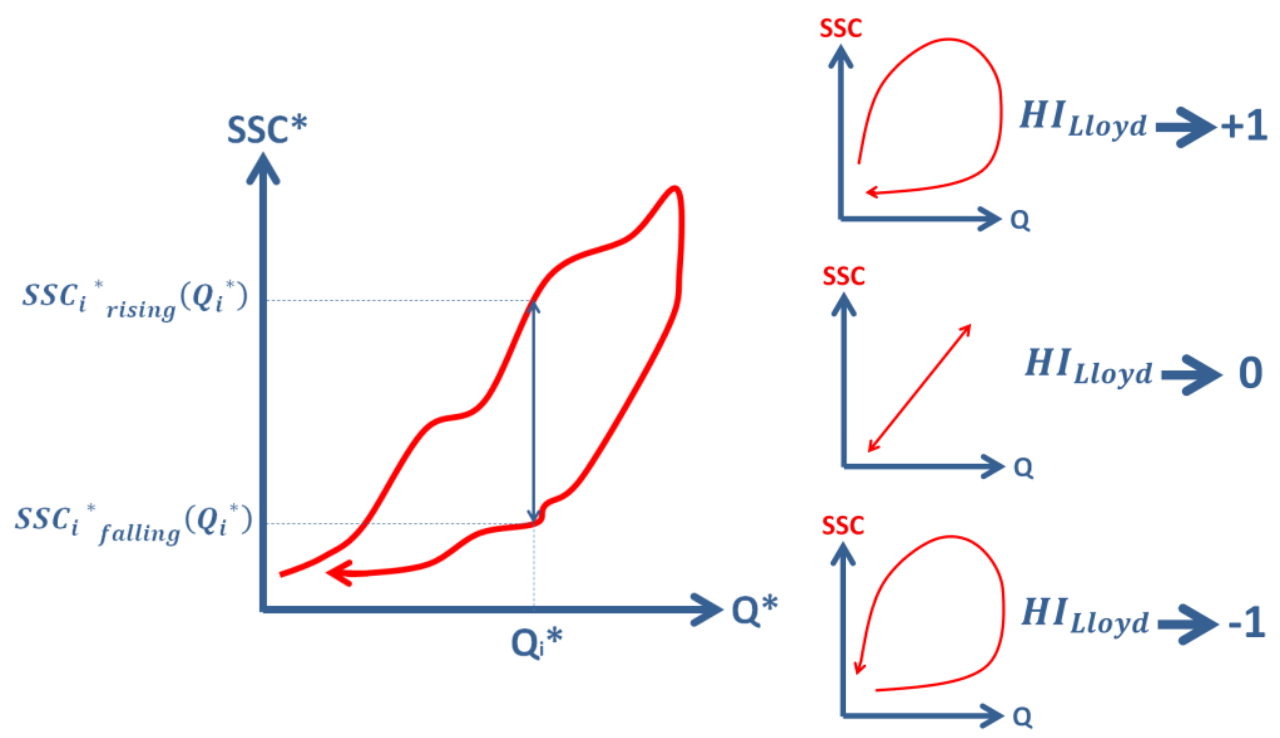

Fig. 2. Principle of hysteresis index calculation proposed by Llyod et al. (2016).

The steps to compute this index for a given event are detailed below. Q and SSC were first normalized to be able to compare events with different magnitudes (Eq. (2) and Eq. (3)). The difference between normalized $\operatorname{SSC}\left(S S C^{*}\right)$ of the rising and falling limb was calculated. This difference was computed for 100 values of $Q^{*}$ from 0.01 to 1 . The Lloyd hysteresis index $\left(H I_{\text {Lloyd }}\right)$ was the mean of these differences (Eq. (1)). As shown in Figure 2 , Lloyd HI tends to +1 for clockwise loops and to -1 for counter clockwise loops. It is equal to 0 if there is no loop.

$$
\begin{aligned}
& H I_{\text {Lloyd }}=\operatorname{mean}\left[S S C_{i}{ }^{*} \text { rising }\left(Q_{i}{ }^{*}\right)-S S C_{i}{ }^{*} \text { falling }\left(Q_{i}{ }^{*}\right)\right] \text { with } i \in[1 \%, 100 \%] \\
& S S C_{i}{ }^{*}=\frac{S S C_{i}-S S C_{\min }}{S S C_{\max }-S S C_{\min }} \\
& Q_{i}^{*}=\frac{Q_{i}-Q_{\min }}{Q_{\max }-Q_{\min }}
\end{aligned}
$$

In addition to this continuous index, we classified each flood as clockwise, counter clockwise or complex/straight loops. Clockwise was considered if more than $80 \%$ of differences between $S S C_{\text {rising }}^{*}$ and $S S C_{\text {falling }}^{*}$ were positive whereas counter clockwise were defined with $80 \%$ of negative differences. Complex/straight classification was used otherwise. 


\subsection{Event definition}

To be able to analyze hysteresis patterns a selection of flood events was needed. To select both SSC and Q variables, we chose to use the SSL time series to select events. For each catchment, an event was selected if a minimum peak of SSL was reached and if it exceeded all preceding and following values during a certain time. To evaluate the efficiency of the method, we defined for all the rivers the values of SSL, Q and SSC above which $90 \%$ of cumulative SSL was transported ( $\mathrm{SSL}_{90 \%}, \mathrm{Q}_{90 \%}$ and $\mathrm{SSC}{ }_{90 \%}$ ). Then after selecting the events, the cumulative fluxes transported above these limits and not selected were compared to those selected and used for the hysteresis analysis (Figure 3).

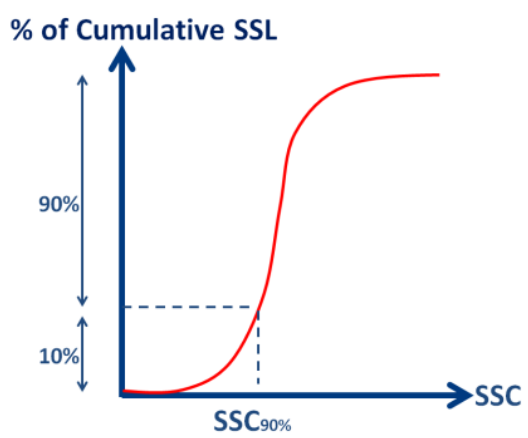

Fig. 3. Definition of $\mathrm{SSC}_{90 \%}, 90 \%$ of total cumulated SSL transported above this limit.

\section{Results}

\subsection{Sampling efficiency}

Using the methodology detailed above, we selected several flood events for all the rivers. We obtained a minimum of nearly 100 events for the shorter time series (2 years) and nearly 2000 events for the longer one (10 years). These selected events represented the biggest part of total suspended fluxes for all the rivers (Table 3). The total mass not selected and transported above critical threshold values of SSL, Q or SSC (respectively $\mathrm{SSL}_{90 \%}, \mathrm{Q}_{90 \%}$ and $\mathrm{SSC}_{90 \%}$ ) was really low. For instance, only $6 \%$ of the cumulated fluxes not selected were transported above $\mathrm{SSL}_{90 \%}, \mathrm{Q}_{90 \%}$ and $\mathrm{SSC}_{90 \%}$ for the Glandon River which was the worst result. Thus, a quantitative analysis of hysteresis phenomena on these events would provide a representative point of view of general trends. Large differences on $\mathrm{SSC}_{90 \%}$ were obtained between southern pre-Alps basins and high mountain basins. SSL of the previous ones are transported with much higher SSC.

Table 3. Sampling efficiency. MNS denotes the \% of the cumulated mass not selected above a certain threshold ( $\mathrm{SSL}_{90 \%}, \mathrm{Q}_{90 \%}$ and $\mathrm{SSC}_{90 \%}$ ).

\begin{tabular}{lccccccc}
\hline River & $\begin{array}{c}\mathrm{SSL}_{90 \%} \\
{[\mathrm{~kg} / \mathrm{s}]}\end{array}$ & $\begin{array}{c}\mathrm{SSC}_{90 \%} \\
{[\mathrm{~g} / \mathrm{l}]}\end{array}$ & $\begin{array}{c}\mathrm{Q}_{90 \%} \\
{[\mathrm{~m} 3 / \mathrm{s}]}\end{array}$ & $\begin{array}{c}\text { MNS } \\
\mathrm{SSL}_{90 \%} \\
{[\%]}\end{array}$ & $\begin{array}{c}\text { MNS } \\
\mathrm{SSC}_{90 \%} \\
{[\%]}\end{array}$ & $\begin{array}{c}\text { MNS } \\
\mathrm{Q}_{90 \%} \\
{[\%]}\end{array}$ & $\begin{array}{c}\text { number } \\
\text { of } \\
\text { event }\end{array}$ \\
\hline Arc & 2.4 & 0.2 & 17 & 5 & 5 & 4 & 654 \\
Ferrand & 0.6 & 0.2 & 4 & 2 & 2 & 3 & 599 \\
Romanche & 1.2 & 0.1 & 14 & 3 & 3 & 3 & 1974 \\
Arvan & 11.3 & 1.7 & 8 & 1 & 1 & 2 & 534 \\
Glandon & 0.4 & 0.1 & 5 & 6 & 6 & 6 & 527
\end{tabular}




\begin{tabular}{lccccccc} 
Drac & 1.5 & 0.1 & 25 & 0 & 0 & 1 & 571 \\
Bléone & 2.1 & 0.3 & 17 & 3 & 3 & 3 & 107 \\
Asse & 32.9 & 4.0 & 24 & 1 & 1 & 0 & 193 \\
Buech & 54.1 & 2.6 & 35 & 0 & 0 & 0 & 101 \\
Bès & 39.7 & 9.5 & 12 & 3 & 2 & 0 & 94 \\
\hline
\end{tabular}

\subsection{Dominant hysteresis response}

Table 4 provides a summary of the dominant hysteresis loops on the 10 Alpine rivers. Considering the number of events, several rivers exhibited no general trend with median or mean values of HI around zero. However, three rivers were mainly characterised by clockwise loops (Buech, Bléone and Drac rivers) and one by counter clockwise loops (Ferrand river). A large variability was observed with standard deviation from 0.2 to 0.35 on HI values. Considering the mass transported with a given hysteresis led to different results. For instance, the Asse river had a mean HI of -0.03 but $60 \%$ of the mass was transported with clockwise loop patterns as compared to $11 \%$ with counter clockwise hysteresis. In that case, few rare clockwise events seemed to flush the system. This would mean that transport efficiency could be really different from one hysteresis loop to another. In most cases ( 7 over 10 rivers) clockwise loops transported more than counter clockwise ones.

Table 4. Hysteresis results for the 10 Alpine rivers. Sd denotes standard deviation.

\begin{tabular}{lcccccc}
\hline River & median(HI) & mean(HI) & $\operatorname{Sd}(\mathrm{HI})$ & $\begin{array}{c}\text { Mass } \\
\text { clockwise } \\
{[\%]}\end{array}$ & $\begin{array}{c}\text { Mass } \\
\text { counterclock } \\
{[\%]}\end{array}$ & $\begin{array}{c}\text { Mass } \\
\text { complexe/straight } \\
{[\%]}\end{array}$ \\
\hline Arc & 0.02 & 0.01 & 0.28 & 27 & 32 & 42 \\
Ferrand & -0.23 & -0.25 & 0.22 & 9 & 69 & 22 \\
Romanche & -0.03 & -0.01 & 0.25 & 25 & 29 & 46 \\
Arvan & 0.02 & 0.02 & 0.26 & 33 & 27 & 39 \\
Glandon & 0.02 & 0.03 & 0.24 & 44 & 24 & 33 \\
Drac & 0.13 & 0.14 & 0.22 & 41 & 24 & 35 \\
Bléone & 0.15 & 0.14 & 0.25 & 84 & 2 & 14 \\
Asse & -0.03 & -0.03 & 0.23 & 60 & 11 & 29 \\
Buech & 0.12 & 0.10 & 0.35 & 35 & 14 & 50 \\
Bès & 0.02 & 0.08 & 0.32 & 42 & 5 & 53 \\
\hline
\end{tabular}

\section{Factors influencing hysteresis patterns}

The main hysteresis characteristics (Table 4) were analysed in the light of the geomorphological features of the catchments characteristics (Table 1). The mass transported within a given hysteresis loop category was strongly correlated with certain catchment properties as shown in Table 5. For counter clockwise loops, the mass transported decreased with the fraction covered by forest (FO, Figure 4a), the active width (W) and the basins size (A) while it increased with the fraction with no or low vegetation cover (NO, Figure $4 \mathrm{~b}$ ), the bed slope (S) and the glacier cover $(\mathrm{Gl})$. Opposite trends were observed for Clockwise loops. Lower correlations were obtained with catchment geology. 


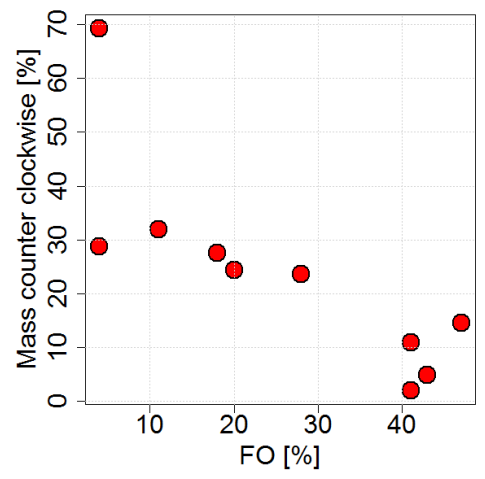

a)

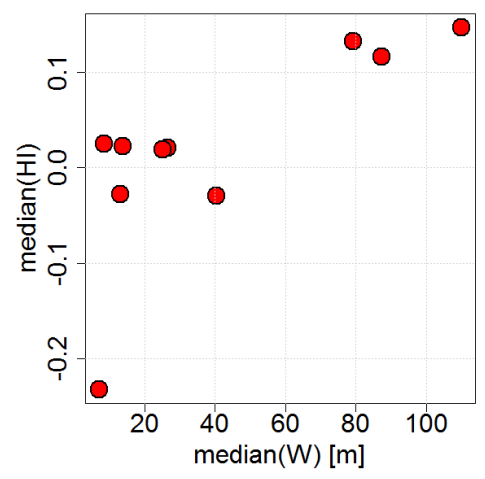

c)

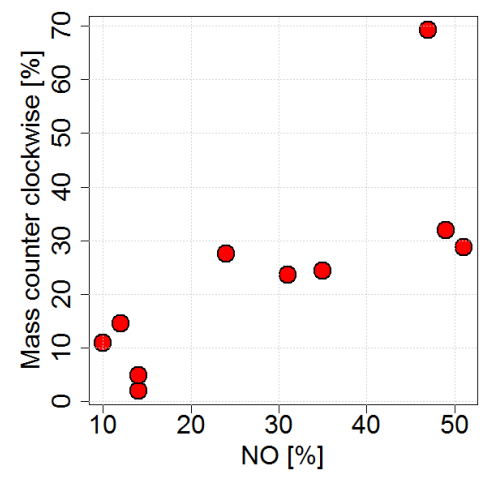

b)

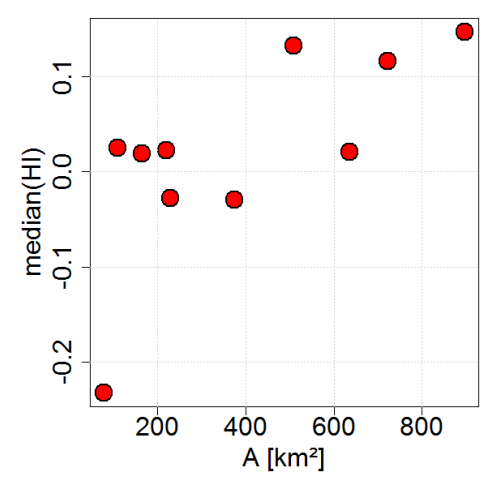

d)

Fig.4. Hysteresis parameters as a function of catchment characteristics.

These results suggest that catchments with large eroded areas and step pool bed morphology (Arvan, Glandon and Ferrand) will have mainly sources of sediments located far from the outlet or on hillslopes leading to counter clockwise loops. On the contrary catchments including braided rivers (Drac, Buëch and Bléone) or which have intermediate storage zones with gentle slopes and large active widths are less connected to primary sources. The bed of these rivers might act as a buffer and as a significant source of fine sediments [8]. Mainly clockwise loops were thus observed in such rivers with median HI higher than 0.1. An increase in HI was linked to an increase in active width and a decrease in bed slope (figure 4-c, Table 5). These river bed properties could be seen as a proxy of the presence of buffer zones and stocks of fine sediments in the bed. This sediment discontinuity seems to follow the same trend with increasing catchment size (figure 4-d, Table 5).

Table 5. Pearson correlation matrix between hysteresis results and catchment characteristics. Significant relationships ( $95 \%$ confidence interval) are highlighted in bold.

\begin{tabular}{lccccccccc}
\hline & $\mathrm{S}$ & $\mathrm{W}$ & $\mathrm{A}$ & $\mathrm{NO}$ & $\mathrm{FO}$ & $\mathrm{Gl}$ & $\mathrm{S} F \mathrm{H}$ & $\mathrm{HR}$ & $\mathrm{RR}$ \\
\hline HImed & $\mathbf{- 0 . 7 4}$ & $\mathbf{0 . 7 4}$ & $\mathbf{0 . 7 0}$ & $\mathbf{- 0 . 4 7}$ & $\mathbf{0 . 5 6}$ & $\mathbf{- 0 . 4 2}$ & $\mathbf{0 . 4 0}$ & $\mathbf{- 0 . 4 8}$ & $\mathbf{- 0 . 1 1}$ \\
HImean & $\mathbf{- 0 . 7 3}$ & $\mathbf{0 . 6 8}$ & $\mathbf{0 . 6 1}$ & $\mathbf{- 0 . 4 9}$ & $\mathbf{0 . 5 8}$ & $\mathbf{- 0 . 4 3}$ & $\mathbf{0 . 4 1}$ & $\mathbf{- 0 . 4 9}$ & $\mathbf{- 0 . 1 2}$ \\
Ms $_{\text {clock }}$ & $\mathbf{- 0 . 5 9}$ & $\mathbf{0 . 6 6}$ & $\mathbf{0 . 5 5}$ & $\mathbf{- 0 . 7 0}$ & $\mathbf{0 . 7 1}$ & $\mathbf{- 0 . 5 8}$ & -0.05 & 0.15 & $\mathbf{- 0 . 1 9}$ \\
Ms $_{\text {counter }}$ & $\mathbf{0 . 7 4}$ & $\mathbf{- 0 . 5 5}$ & $\mathbf{- 0 . 4 8}$ & $\mathbf{0 . 7 5}$ & $\mathbf{- 0 . 8 1}$ & $\mathbf{0 . 5 0}$ & -0.31 & 0.28 & $\mathbf{0 . 1 3}$
\end{tabular}




\begin{tabular}{llllllllll}
$\mathrm{Ms}_{\text {straight/complex }}$ & -0.16 & -0.25 & -0.18 & 0.01 & 0.07 & 0.20 & $\mathbf{0 . 5 5}$ & $\mathbf{- 0 . 6 8}$ & 0.12 \\
\hline
\end{tabular}

This analysis suggests that SSL in mountainous rivers can be driven in certain cases by hillslope or first order tributary erosion processes while for others, bed production seems to control SSL dynamics.

\section{Conclusion}

A quantitative analysis of hysteresis loops between suspended load and flow rate was performed for 10 Alpine rivers with various characteristics. It allowed us to assess which of hillslope or bed production dominates for each catchment. Prevailing hysteresis was found to be correlated with watershed properties. Catchments exhibiting large areas with no or low vegetation cover, steep and narrow river bed were mainly characterised by counterclockwise hysteresis loops, suggesting sediment sources were located far from the outlets. On the other hand, braided rivers with large active widths and gentle slopes were characterised mainly by clockwise loops, suggesting that the river bed itself could be the main provider of fine sediments acting as a buffering area. Deposition and remobilization processes taking place in that kind of streams, as well as the interactions between suspended load and bedload, need to be considered and studied in future works.

Acknowledgements: This study was funded by IRSTEA, EDF-DTG (Electricité De France Direction Technique Générale) and the French National Research Agency (STREAMS Project).

\section{References}

1. Klein, M., Anti clockwise hysteresis in suspended sediment concentration during individual storms: Holbeck Catchment; Yorkshire, England. Catena, 1984. 11: p. 251-257.

2. Williams, G.P., Sediment concentration versus water discharge during single hydrologic events in rivers. Journal of Hydrology, 1989. 111: p. 89-106.

3. Park, J. and J.R. Hunt, Coupling fine particle and bedload transport in gravelbedded streams. Journal of Hydrology, 2017. 552: p. 532-543.

4. Wood, P.A., Controls of variation in suspended sediment concentration in the River Rother, West Sussex, England. Sedimentology, 1977. 24: p. 437-445.

5. Nistor, C.J. and M. Church, Suspended sediment transport regime in a debris-flow gully on Vancouver Island, British Columbia. Hydrological Processes, 2005. 19(4): p. 861-885.

6. Lloyd, C.E., et al., Using hysteresis analysis of high-resolution water quality monitoring data, including uncertainty, to infer controls on nutrient and sediment transfer in catchments. Sci Total Environ, 2016. 543(Pt A): p. 388-404.

7. Navratil, O., et al., Temporal variability of suspended sediment sources in an alpine catchment combining river/rainfall monitoring and sediment fingerprinting. Earth Surface Processes and Landforms, 2012. 37(8): p. 828-846.

8. $\quad$ Navratil, O., et al., Assessment of intermediate fine sediment storage in a braided river reach (southern French Prealps). Hydrological Processes, 2010. 24(10): p. 1318-1332. 